\title{
JOCS DE LLENGUATGE EN ESCENA
}

\section{LANGUAGE GAMES ON STAGE}

\author{
JoAn Sellent Arús \\ Universitat Autònoma de Barcelona \\ jsellent@gmail.com
}

Resum: Aquest article gira a l'entorn de la presència, en l'escena catalana, del contrast de registres lingüístics en unes versions que van més enllà del marc estricte de la normativa oficial. A aquest efecte, s'utilitzen com a objectes d'anàlisi les versions de dues peces teatrals dutes a terme en contextos històrics i sociopolítics molt diferents -la de Joan Oliver de Pygmalion, de G.B. Shaw (1957), i la de Joan Sellent de Translations, de Brian Friel (20I4) - i se’n ressalten les afinitats i diferències, tant pel que fa a la tria dels materials lingüístics com als objectius dramatúrgics i ideològics.

Tant en una versió com en l'altra, la transgressió freqüent de les normes de la Secció Filològica de l'Institut d'Estudis Catalans respon a unes finalitats que, en el fons, reivindiquen la genuïnitat, la força expressiva i l'eficàcia dramàtica d'unes opcions lingüístiques que la normativa oficial es resisteix a acceptar.

Paraules clau: traducció teatral, normes gramaticals, registres, genuïnitat, adequació expressiva vs. correcció normativa.

Abstract: This article deals with the presence on the Catalan stage of different versions showing a contrast of linguistic registers which contravene official language norms. The versions analysed are two theatre plays belonging to widely differing historical and socio-political contexts: Joan Oliver's rendering (1957) of G.B. Shaw's Pygmalion, and Joan Sellent's version (2014) of Brian Friel's Translations. Affinities and divergences are highlighted, both with regard to choice of linguistic material and to dramaturgical and ideological goals.

The frequent violation by both versions of the norms established by the Secció Filològica de l'Institut d'Estudis Catalans is ultimately intended to vindicate the genuine character, expressive force and dramatic effectiveness of a set of linguistic options that official norms are unwilling to accept.

Key words: translation for the theatre, grammatical norms, registers, genuineness, expressive adequacy vs. adjustment to norms. 


\section{JOAN SELLENT ARÚS}

\section{JOCS DE LLENGUATGE EN ESCENA}

En aquest article em proposo comentar, així com il-lustrar amb exemples que en subratllin les afinitats i divergències pel que fa a les estratègies utilitzades, dues versions concretes al català d'unes obres teatrals en llengua anglesa on el joc idiomàtic i el contrast entre nivells de llenguatge ocupen un lloc primordial en l'aparell escènic.

\section{EL PIGMALIÓ DE JOAN OLIVER}

ROSETA: És aixòs lo que aprenen als col-lègits de pago? L'establiment a la missèria! [...] Dòs goiti, ia podria pagar-me la mercancia avariada [...] Tinc que retratar-me, comprèn el xesto?

(Oliver, 1989)

L’any 1957, quan l'Agrupació Dramàtica de Barcelona (= ADB) va estrenar la peculiar traducció/adaptació del Pygmalion de George Bernard Shaw que havia elaborat Joan Oliver, els espectadors van poder sentir una variant del català absolutament insòlita en els escenaris de l'època.

Feia divuit anys que s'havia acabat la guerra civil, i la dictadura franquista continuava relegant el català a unes catacumbes on, tímidament, s'obria alguna escletxa que li començava a permetre una migradíssima presència pública. L'actitud resistencial

I. M'he basat en el text publicat a Versions de teatre de Joan Oliver (Barcelona: Edicions Proa, 1989, pp. 753-835), que conté alguns canvis menors respecte a la primera versió de 1957. 
que caracteritzava els responsables d'aquesta presència pública del català com a llengua de cultura i d'entreteniment comportava, en la majoria dels casos, la subjecció estricta i sense fissures a un model de llengua rigorosament cenyit a les normes de la Secció Filològica de l'Institut d'Estudis Catalans. Qualsevol desviació d'aquestes normes —o, per ser més exactes, qualsevol concessió als vulgarismes i llicències de la parla popular- hauria agreujat encara més, en opinió d'aquests sectors de la resistència cultural, el perill en què innegablement es trobava la supervivència de la llengua catalana.

I és per això que aquesta aposta radical de Joan Oliver per traslladar a l'escena el català més «impur» de les classes populars va representar un fenomen clarament excepcional. Aquell mateix any, la mateixa ADB estrenava Primera història d'Esther, de Salvador Espriu (escrita el 1948), un text teatral que el mateix autor va qualificar de testament i epitafi de la llengua catalana. Convençut que el català com a llengua de cultura, i sobretot com a llengua viva, es trobava en un estat agònic, Espriu va abocar en aquest text tota la seva saviesa literària i lingüística i tota la seva memòria com a parlant, amb la intenció de produir un bigarrat i exhaustiu inventari dels recursos expressius de la seva llengua, des dels més cultes fins als més populars.

Salvador Espriu, però, va mantenir-se en tot moment (amb molt escasses i discretes excepcions) dins l'àmbit del que recollien els diccionaris, complementant l'opció amb l'ús d'alguna paraula o formació derivativa inventada però servint-se en tot moment dels mecanismes interns de la llengua. Haver-hi inclòs mostres flagrants de contaminació per part de la llengua veïna hauria anat en contra del seu afany de mostrar la riquesa autònoma del català i de deixar constància, per a futures generacions, del tresor patrimonial que havien perdut.

Oliver, en canvi, va agafar el toro per les banyes i va voler plasmar en escena, sense concessions, el català de les classes populars (i, més concretament, de les classes populars urbanes). Va optar, a més, per traslladar el Londres de I9I3 a la Barcelona de I957, convertir el Covent Garden en el Palau de la Música Catalana, rebatejar Eliza Doolittle com a Roseta Fernandes i el professor Higgins com a Martí Jordana. Roseta, una florista de la Rambla, s'expressava en un xava barceloní descarnat, generosament nodrit amb aquells trets — tant lèxics com morfosintàctis, locucionals i fonètics- que caracteritzaven aquesta variant del català com una de les més «impures» i contaminades. És a dir: substituïa amb un dialecte urbà autòcton el cockney londinenc amb què s'expressa el personatge de l'original de G. B. Shaw.

Aquesta opció d'anar més enllà de la transposició lingüística i traslladar el text a l'espai i al context sociocultural més propers a l'espectador català dels anys 50 del 
segle Xx és la que va triar Joan Oliver, però no era pas l'única possible: hauria pogut fer que l'acció continués tenint lloc al Londres de principi de segle i que els personatges mantinguessin els seus noms anglesos. Probablement, si va tirar per aquest camí és, entre altres raons, perquè la parla que havia decidit assignar a la florista (abans de ser lingüísticament reeducada pel professor) li devia semblar massa marcadament barcelonina per resultar versemblant que la noia fos londinenca i es digués un nom tan anglès com Eliza Doolittle.

Pel que fa a les intencions subjacents a aquest experiment lingüístic, i vista la manera com són representats els dos nivells de llenguatge que conviuen en aquesta versió catalana (exemplificats en la parla popular de la florista Roseta i la parla culta del professor Jordana), hi ha raons de pes per deduir que, en el fons, l'objectiu d'Oliver no era precisament (en contrast amb el de G.B. Shaw) condemnar sense pal-liatius el parlar estripat de la florista, sinó en realitat reivindicar-lo; o més ben dit, tal com diu Joan Casas, afegir «a la irònica crítica social una crítica solapada al model de llengua»; $i$ afegeix Casas (1989: I7-I8):

La polaritat Jordana/Roseta és la del català "ben parlat" de les classes altes confrontat amb el català "mal parlat", el xava de les classes populars — que en la forma que Oliver li dóna és un sensacional pastitx, una síntesi feta amb records de les parles populars de preguerra, l'invent d'un llenguatge ja inexistent que, justament per la seva desaparició, hauria d'haver fet reflexionar el bon públic burgès que va anar a veure l'estrena-, i, al fil del procés d'aprenentatge de Roseta, Oliver no estalvia tampoc les ironies contra la tendència al cultisme pedantesc, a la hipercorrecció que anul-la tota vitalitat i és símptoma d'endogàmia tribal. Oliver, amb el cor decantat cap a la banda del poble, precisa amb frases afegides al final de Shaw per esbandir ambigüitats i deixar clar que la relació Roseta-Jordana no és un amor impossible, sinó finalment el contrast entre algú que aprèn (Roseta) i algú que no aprèn res (Jordana).

Ja en el text original de Shaw, no és gens difícil que les simpaties de l'espectador o del lector es decantin més per la florista que no pas pel professor que s'obstina a sotmetre-la a un experiment d'educació lingüística i social, oblidant massa sovint que no és un conillet d'índies sinó un ésser humà. La versió catalana, però, va més enllà i aconsegueix incrementar l'antipatia que desperten l'actitud i el caràcter de l'atrabiliari professor Jordana per la via del model de llengua que fa servir: un català correctíssim, això sí, però encarcarat, esquitxat amb molts dels tics més afectats del noucentisme i amb més limitacions expressives que el de la florista Roseta abans de ser sotmesa a l'experiment (un cop «reeducada» lingüísticament, Roseta parla un català tan o més encarcarat que el del seu professor). 
En aquest sentit, doncs, podem afirmar que l'objectiu de Joan Oliver no dista tant com pugui semblar del de la Primera història d'Esther espriuana, perquè el seu Pigmalió també és una elegia per un model de llengua popular que es troba en greu perill d'extingir-se, víctima d'una situació política de repressió del català i de contaminació galopant per part del castellà però també d'aquella «hipercorrecció que anul.la tota vitalitat i és símptoma d'endogàmia tribal», i que és precisament, per a la resistència cultural d'aquells anys, l'únic model de català que cal defensar per no desaparèixer com a comunitat de parlants d'una llengua amenaçada. El toc d'alerta de Joan Oliver, precisament un dels representants més conspicus del tardonoucentisme, té per això mateix un valor especial i està en plena consonància amb el seu caràcter d'intel.lectual heterodox i lliurepensador.

\section{TRANSLATIONS: UNA EXPERIÈNCIA PERSONAL}

MAIRE: No hi ha dingú més? No hi ha estudi, aquesta tarda? [...] goita, goita, quin quadro més bonic... [...] Oooh... la collita més bona que recorden els més veis, diuen; pro io no en vui veure cap més, com aquesta. [...] Els soldats inglesos [...] ia pugen a donàns-e un cop de mà. No aplego re de lo que diuen, ni ells m'entenen a mi...

$(\text { Friel 198I) })^{2}$

Quan vaig rebre l'encàrrec de traduir al català la peça teatral de Brian Friel Translations, ${ }^{3}$ un text que gira a l'entorn d'un eix central sobre llengua i identitat, em vaig haver d'enfrontar a un peculiar recurs escènic que el dramaturg irlandès va decidir aplicar al seu text original, i que passaré a descriure tot seguit.

Basada en uns fets històrics emmarcats en la Irlanda de la primera meitat del segle XIX, Translations situa l'acció en una petita comunitat rural del nord-oest d'Irlanda on acaba d'arribar un destacament de geògrafs de l'exèrcit britànic amb la missió d'iniciar un procés dràstic i expeditiu d' «anglificar» el territori i la seva població, la major part de la qual té el gaèlic com a llengua única. El procés consistirà a traduir o adaptar a l'anglès tots els topònims, paral-lelament a l'estratègia del govern britànic d'iniciar la construcció d'escoles públiques amb l'anglès com a única llengua vehicular i d'aprenentatge.

2. Versió catalana de l'autor. Traducció inèdita.

3. Estrenada a l'espai escènic de la Biblioteca de Catalunya (Barcelona) el 29 de gener d'aquest any, amb el títol de Traduccions/Translations i sota la direcció de Ferran Utzet. 
Dalt del'escenari, per tant, conviuen uns personatges que només parlen la varietat irlandesa del gaèlic amb uns altres que tan sols parlen anglès, i només la presència d'un intèrpret fa relativament possible la comunicació entre aquests dos grups de parlants monolingües. Fins aquí tot sembla concordar amb situacions perfectament creïbles i freqüents a la vida real; però resulta que, en la realitat virtual de l'obra — i aquesta és la peculiaritat de què parlàvem abans—, la diferència de llengües no és més que una il.lusió, senzillament perquè tots els personatges parlen en anglès.

Sospesades les possibles estratègies a seguir en la traducció, $\mathrm{i}$ tenint molt present la prioritat de ser fidel a les intencions de l'original i a l'artifici escènic pel qual havia optat l'autor, la pura lògica no em va deixar cap altra via possible — si no volia cometre un greu pecat de traïció- que fer parlar tots els personatges en català.

D'altra banda, però, tampoc no vaig poder obviar un altre recurs que en aquesta obra té un pes no menys decisiu: el fet que els personatges autòctons que representa que només parlen gaèlic, a diferència dels que han vingut d'Anglaterra, s'expressen en un anglès d'Irlanda acolorit amb els nombrosos trets distintius (lèxic, sintaxi, locucions i frases fetes, accent, entonació) que en fan una de les variants dialectals de l'anglès amb més personalitat pròpia i amb un substrat més detectable de la llengua suplantada.

I és a l'hora de decidir com recreava aquest contrast dialectal i de nivells de llenguatge quan vaig buscar precedents en traduccions catalanes on aparegués un joc lingüístic poc o molt comparable. I no cal dir que el primer que em va venir al cap va ser el Pigmalió de Joan Oliver, i és aquesta la referència principal que vaig tenir present, tant per la via de les afinitats com de les divergències.

Oliver, com ja hem vist, no únicament va traduir (molt lliurement, per cert) la lletra del text de Shaw sinó que va dur a terme una maniobra radical de transposició del context geogràfic, històric i social. No era això, en canvi, el que jo havia de fer amb Translations, perquè aquí no es tractava de traslladar l'acció, ni el lloc, ni l'època ni els personatges al nostre context més immediat, sinó de conservar l'emplaçament històric i geogràfic de l'original (la Irlanda de 1833) i de mantenir, malgrat la convenció que parlessin en català, la condició de britànics i els noms originals de tots els personatges.

Em va semblar, per tant, que hauria anat perillosament en contra de la versemblança si hagués optat per fer parlar alguns dels personatges en una variant dialectal excessivament acotada i identificable (en mallorquí, posem per cas); és a dir, si l'opció d'Oliver per una variant concretíssima del català estava plenament justificada i en perfecta consonància amb el lloc i l'època en què transcorre la seva versió, la decisió 
de fer el mateix en la meva traducció de l'obra de Friel hauria resultat difícilment justificable; o, com a mínim, hauria introduït un element de distracció que, al meu entendre, hauria anat en greu detriment de la versemblança ("Què hi fan, a Irlanda, aquests mallorquins?», s'hauria pogut preguntar l'espectador).

Fetes aquestes reflexions, l'única estratègia que em va semblar oportuna va ser la de fer que aquells personatges que a l'original parlen amb uns trets irlandesos més marcats s'expressessin (en contrast amb el català estàndard que vaig decidir assignar als militars) amb uns quants tocs d'un català popular, tan intemporal i tan poc identificable amb cap dialecte concret com fos possible; ${ }^{4}$ un model de llengua, d'altra banda, que, amb totes les seves «imperfeccions», és tan històricament genuí com el català beneït per la normativa oficial; un parlar de la bona gent del poble que sovint, injustament, ha arrossegat l'estigma d'impur i d'il.legítim, però que dista tant del model normatiu estricte com de l'híbrid empobridor que tendeixen a gastar les noves generacions o del català ortopèdic que sovint ens ofereixen els mitjans de comunicació.

\section{FENÒMENS DE PARLA: COINCIDÈNCIES I DIVERGÈNCIES}

Era evident que, a l'hora de triar els recursos idiomàtics, calia tenir clar quins mecanismes dels que havia aplicat Joan Oliver em podien servir i quins altres calia descartar si no volia que entressin en contradicció amb els criteris pels quals havia optat.

Passant a exemples concrets: en el parlar apitxat de la Roseta de Pigmalió apareixen nombrosos ensordiments (missèria, cossa, dessalmats [aquí hi ha el doble fenomen de l'ensordiment i el castellanisme lèxic], elssuis [per els ulls], elss hi conservi, xesto, trepitxen, xeneral, dotsena, aixuntament, monxetes, xitana, fuixiu, barreixat, pluixa, optxecte, xardí, mitxa, txerrar, etc.), calcs sintàctics i locucionals del castellà (tinc que retratar-me, sempre i quan, al tanto, a bufetada limpia, no coneix el panyo, etc.), una profusió de castellanismes lèxics (mercancia, derrotxe, suelto, menos, compra-venta, escaparate, lletrero, algo, pues, jusgat, sinvergüensa, txibato, acomodo, sonsacar, arrastrada, desperdici, tio, enteris, hasta, bueno, socorro, ojo [com a exclamació], descaro, els demés, vereno, tumulto, dos [femení], sablasso, antes, sofoco, traje, gasto, etc.).

4. Sóc conscient que, tot i aquest afany de «no identificació», alguns dels trets lingüístics aplicats potser són més identificables amb el dialecte central (que és el meu i el de bona part dels actors i dels espectadors potencials de la funció) que no pas generalitzables a tot el territori catalanoparlant. 
De tots aquests fenòmens de parla que acabo d'enumerar, no em va semblar coherent amb la parla rural dels vilatans irlandesos recórrer ni a l'ensordiment ni als calcs sintàctics i locucionals del castellà, massa identificables amb el xava barceloní. Pel que fa als castellanismes lèxics, no vaig renunciar a incloure-n'hi algun (aparato, puesto, apretar...), però d'una manera molt més dosificada i amb el criteri, reconec que bàsicament intuïtiu, que no resultessin excessivament anacrònics (avançats en el temps, en aquest cas) en una obra que té lloc a la primera meitat del segle XIX.

Podríem dir, però, que en general hi ha més coincidències que no pas divergències. La majoria dels trets que caracteritzen la parla urbana de la florista d'Oliver em va semblar que podien resultar igualment creïbles en boca dels parlants rurals de la meva traducció, perquè pertanyen a una època en què, malgrat les diferències ja existents i innegables, hi havia un parentiu molt més estret que avui dia entre la parla popular barcelonina i la de la resta de Catalunya. Només llegint, posem per cas, un escriptor del segle XIX tan barceloní com Emili Vilanova i contrastant-lo amb el català popular que es podia sentir a totes les poblacions de Catalunya (grans, mitjanes o petites; rurals, semirurals o industrials) fins fa cinquanta o seixanta anys, ja tindrem una prova inequívoca de fins on podia arribar aquest parentiu.

La florista Roseta, d'una banda, i de l'altra Doalty, Maire i Bridget (els tres joves rurals de Translations, que són els personatges amb més trets de parla popular de l'obra) comparteixen el io, el ia, el vui, els uis i els veis (per jo, ja, vull, ulls i vells); el dòs i el vòs (per doncs i vols), l'aixis i l'aixins; l'encabat, el llavons, el llavores, l'allavores i el llavonses; el per'xò, el pro (per però), el podé (per potser), el 'nar i el per'qui per'llà; el goita, l'aiga i la llenga; el col.lègit i el màpat; el dingú i el domés; uns tenen les oreies vermeies $\mathrm{i}$ uns altres vegilen la canaia o van radere el bestiar; hi ha gent més intel.ligenta i gent més ignoranta; es lleven d'hora al dematí en sense queixar-se; invoquen Nostro Senyor o quansevol atra jerarquia celestial; combinen el res i el re segons el que l'orella els dicta... i, per descomptat, recorren al lo neutre com havia fet tota la vida la bona gent a tots els territoris de parla catalana ("Lo que aprenen als col.lègits», diu la Roseta; "No aplego re de lo que diuen», diu la Maire).

En la meva versió de Translations, com ja he dit més amunt, vaig evitar els calcs sintàctics del castellà però, en canvi, em vaig permetre pleonasmes pronominals com ara "Hi vaig anar-hi» $\mathrm{O}$ "M'ho va ensenyar-m'ho", reduccions pronominals i vocals de suport pròpies de la llengua oral espontània (centrem's-e, canvieu's-e, donäns-e, fentels-hi); davant d'infinitius, si d'una banda vaig evitar la perífrasi verbal «tenir que + 
infinitiu», vaig procurar, al servei de la col-loquialitat històrica, no tan sols no evitar sinó potenciar l'alternativa "tenir de», tan avalada per la tradició com genuïna i de formació autònoma (és a dir, aliena a qualsevol influència del castellà). Recursos que, per altra banda, són absents al Pigmalió.

Tornant a la versió de Joan Oliver de la peça de G. B. Shaw, ja he apuntat més amunt — però seria injust no insistir-hi- que el parlar xava i estripat de la Roseta, amb el seu cúmul de solecismes i contaminacions, no es queda ni molt menys en un territori que permeti qualificar-lo sense matisos de català empobrit; tot al contrari: a l'altre plat de la balança, Oliver acoloreix la parla de la florista amb uns recursos expressius que a estones fan semblar el registre del professor Jordana encara més opac i encarcarat. Van apareixent-hi molt sovint, combinades amb les simples incorreccions normatives, expressions tan castisses, genuïnes i de creació autònoma com, per citar-ne només una mostra: «Pasterada! Tot a Can Taps!»; «Aquesta sí que serà la nit del lloro!»; «Repari quina púrria de clavells!»; «Ànsia Manela!»; «Quan em trepitxen el voraviu»; «Farà figa»; «Fica-me’l aquí que no tinc butxaques!»; «Grati’s l'armilla, salau»; «Puixa aquí dalt i voràs ta tia!»; «Fer-me la llesca»; «Moca't!»; «La meva honra es pot tirar als fems»; «Barreixat fa catorse»; «No s'hi possi cap pedra al fetxe, xove!»; «Endinya candela, que hi haurà unteris»; «El meu pamet els fa peça»; «L'he vist, herbeta»; «Pela que sí!»; «No es moca amb mitxa màniga»; "Ara tiri pel cap que vulgui»; «Ara li fan el mànec!»; "Vostè té pa a l'ui, mestressa!»; "Qui vol que carregui amb els neulers?»; "Aquest mestre no carbura de dalt»; «Io m’entenc i ballo sola»; «Passi-ho bé tinguin!»; «Ca, barret!»; «Pro a mi si que rai»...

Evidentment, aquí hem de donar la raó a Joan Casas quan qualifica aquesta parla com «un sensacional pastitx, una síntesi feta amb records de les parles populars de preguerra, l'invent d'un llenguatge ja inexistent». Posar en boca d'una florista de la Rambla barcelonina de l'any 1957 tota aquesta riquesa idiomàtica no podia estar al servei de cap altre objectiu que el de plasmar, dalt d'un escenari, no pas la realitat sinó el desig; la ficció, subjacent a tot aquest Pigmalió de Joan Oliver, d'una Barcelona ideal on el català, amb tota la seva varietat de registres, no estava amenaçat, era present en tots els àmbits de la societat i constituïa la llengua prevalent (o potser única?) de cultura, de comunicació i d'intercanvi social, en un context històric que li permetia funcionar amb absoluta autonomia i llibertat. És a dir: tot el contrari del que estava passant. Abans hem constatat que Oliver va convertir Londres en Barcelona, però potser hauríem de concloure que, en realitat, el que va fer va ser convertir Barcelona 
en una mena de Londres mediterrani: una ciutat on resultés creïble que el professor Jordana es guanyés la vida fent classes de fonètica a uns nous rics que associaven el prestigi social amb el «parlar escaient», i que a una florista de la Rambla li calgués refinar el seu registre lingüístic per poder trobar feina en una floristeria de l'Eixample.

De ben segur que els espectadors de l'època, la majoria pertanyents a una franja de la burgesia barcelonina gairebé residual, la dels catalanistes liberals que s'esforçaven per sobreviure culturalment en aquells anys hostils i a la qual pertanyien la major part dels membres de l'Agrupació Dramàtica de Barcelona, amb Joan Oliver com un dels companys de viatge més il.lustres, estaven més que disposats a deixar en suspensió la incredulitat (per fer servir el terme que va posar en circulació el romàntic anglès S. T. Coleridge) i, ni que fos durant l'estona que durava la representació, deixar-se endur per la il.lusió de realitat que els oferia aquell peculiar i radical anostrament del Pygmalion de Shaw.

Tot era una ficció, una construcció dramàtica que demanava la complicitat del públic per resultar versemblant. Com ho és, de fet, qualsevol producte artístic o pertanyent a qualsevol dels gèneres literaris; i, quan es tracta d'una traducció, evidentment, encara més.

En el cas de Translations, Brian Friel ja va posar més a prova del que és habitual la credulitat del públic en la mateixa redacció del text original. El Pigmalió de Joan Oliver buscava la il.lusió de versemblança per la via de l'adaptació i l'acostament al públic català, i la realitat virtual que presentava era una clara distorsió de la que imperava més enllà del vestíbul del teatre, però això no vol pas dir que aquella realitat no fos objectivament possible. La proposta de Friel, en canvi, demana a l'espectador que entri en el joc de creure's una convenció que no té seu correlat a la vida real: que aquella llengua única que sent en escena són, en realitat, dues llengües diferents.

$\mathrm{Al}$ cap i a la fi, però —i sigui quina sigui la proposta dramatúrgica-, allò que garanteix que l'espectador entri en el joc és la credibilitat de la parla dels personatges; la capacitat, per molt que sigui un artifici tan elaborat com es vulgui, de fer-li idiomàticament creïbles i identificables els enunciats que li arriben des de l'escenari. I això és el que em vaig proposar des del moment d'emprendre l'aventura de traslladar al català l'obra de Brian Friel. El català que parlen els joves irlandesos rurals (i sé que aquesta frase mateixa ja delata el caràcter il.lusori de tota traducció) no deixa de ser, com el que parla la florista Roseta Fernandes, un artifici, una il.lusió de realitat. $\mathrm{Si}$ Joan Oliver, a part dels materials que li fornia el seu bagatge literari, va pouar en 
la memòria lingüística personal per construir el seu artifici, en el meu cas també vaig procurar seguir com bonament vaig poder els criteris que ell havia aplicat: també vaig fer l'esforç d'acompanyar el seguit de vulgarismes que articulen els personatges, sense arribar — ni pretendre-ho- al barroquisme d'Oliver, amb uns modismes i recursos expressius que acolorissin la parla i n'augmentessin el vigor col.loquial.

Sóc conscient, però, que molts dels recursos expressius de la parla popular que vaig posar en boca dels personatges de Traduccions/Translations no pertanyen a la realitat immediata, com tampoc no hi pertanyien els del Pigmalió català. Això, en el cas d'una obra com aquesta que transcorre als anys trenta del segle xIx, ja era oportú que fos així; i, si els resultats de la meva feina han contribuït poc o molt a produir la desitjable combinació de naturalitat i distanciament històric, me’n sentiré lògicament gratificat. El que no estic segur que sigui tan gratificant són les causes d'aquesta sensació de distanciament que el català que parlen els personatges més joves de l'obra pugui produir en els espectadors de trenta anys en avall que la vagin a veure i a escoltar. Si, d'una banda, el fet que gairebé tots els recursos expressius que vaig activar en aquesta traducció procedeixen de la meva memòria lingüística de catalanoparlant nascut a mitjan segle XX i, en canvi, bona part del públic de l'any 2014 no els identifiqui com a pertanyents al seu codi de parla habitual és eficaç al servei d'això que dèiem del distanciament, d'altra banda les connotacions sociolingüístiques que es desprenen d'aquest fet potser ja no són precisament engrescadores. Però això ja són figues d'un altre paner, i donaria per un altre article. Deixem-ho aquí.

Joan Sellent Arús

Universitat Autònoma de Barcelona jsellent@gmail.com

\section{REFERÈNCIES BIBLIOGRÀFIQUES}

Casas, J. (1989) «Pròleg» a Joan Oliver, Versions de teatre, Barcelona, Edicions Proa, pp. $17-18$

Friel, B. (198I) Translations, Londres, Faber \& Faber.

Oliver, J. (1989) Versions de teatre, Barcelona, Edicions Proa, pp. 753-835.

Shaw, B. (2000) Pygmalion: a romance in five acts, Londres, Penguin. 